\title{
Cycloalkenopyridines by ring transformations of diazines and triazines
}

\author{
H. C. van der Plas \\ Laboratory of Organic Chemistry, University of Wageningen, Wageningen, the Netherlands \\ E-mail: hvdplas@skynet.be
}

Dedicated to the 80th birthday of my friend and colleague Czaba Szántay

\begin{abstract}
This paper is a short review on the synthesis of 2,3-cycloalkenopyridines and 3,4cycloalkenopyridines by inter- and intra-molecular cycloadditions.
\end{abstract}

Keywords: 2,3 and 3,4-Cycloalkenopyridines, ring transformations, pyrimidines, pyrazines, 1,2,3 -and 1,2,4-triazines

\section{Introduction}

It is observed that many natural occurring biologically active compounds feature the presence of a cycloalkenopyridine ring as basic skeleton. This observation induced the development of a range of synthetic methods to prepare pharmaceuticals and agrochemicals, containing the cycloalkenopyridine ring as an important building block. ${ }^{1}$ Almost all of these methods are based on condensation of appropriately substituted cycloalkanones with a reagent which is able to form the pyridine ring. Since the six-membered hetaroaromatics, especially diazines and triazines posses the suitable azadiene arrangements to undergo inter-and intramolecular [4+2] inverse

electron demand Diels-Alder cycloadditions leading to pyridines, ${ }^{2,3,4}$ this methodology offers a more recent approach to the synthesis of cycloalkenopyridines. This paper deals with a short review on the synthesis of 2,3-cycloalkenopyridines and 3,4-cycloalkenopyridines by inter- and intra-molecular cycloadditions. 


\section{2,3-Cycloalkenopyridines}

\section{From pyrimidines}

Reacting 5-nitropyrimidine $\mathbf{1}$ with 1-pyrrolidinocyclopentene $\mathbf{2}(\mathrm{n}=1)$ at room temperature for two hours leads to the formation of 6,7-dihydro-3-nitro- $5 H$-cyclopenta[b]pyridine $4 .^{5}$ The reaction was explained by a regiospecific cycloaddition of the double bond of the eneamine across the $\mathrm{N}-1$ and the $\mathrm{C}-4$ atom of the pyrimidine ring, yielding intermediate 3 which by loss of hydrogen cyanide and elimination of pyrrolidine gave the 3,5,6-trisubstituted pyridine 4 (Scheme1). The preference for eneamines to add across $\mathrm{N}-1$ and $\mathrm{C}-4$ in 5-nitropyrimidine and not across C-2 and C-5 is correctly predicted by FMO pertubation theory. ${ }^{6}$

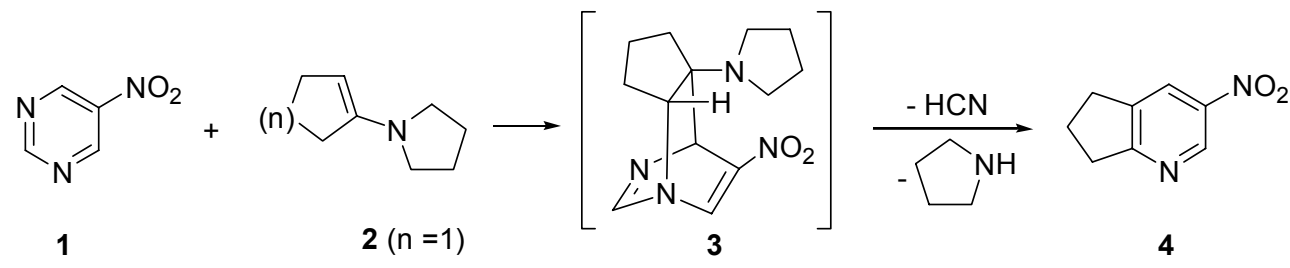

\section{Scheme 1}

The highly strained intermediate 3 could not be isolated, indicating that the addition reaction is the rate-determining step and that the elimination of hydrogen cyanide and pyrrolidine is fast. The fact that under these mild condition reactions the elimination of pyrrolidine so easily takes place, seems to suggest that the trans orientation of the hydrogen and the pyrrolidino group on the bridgehead positions in intermediate $\mathbf{3}$ is converted into the cis-trans orientation yielding intermediate 5 (Scheme 2). This isomerisation is probably facilitated by the presence of the nitro grouping in the aci form 5.

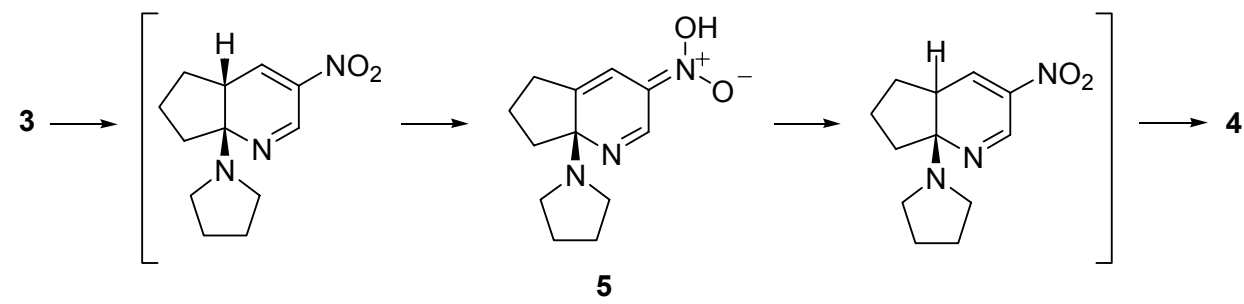

\section{Scheme 2}

Similar ring transformation reactions were also reported in the reaction of 5-nitropyrimidine with the pyrrolidinocycloalkenes $2(n=2,3,4,8)$ leading to the formation of tetrahydro-quinoline $\mathbf{6}^{5} \quad$ 6,7,8,9-tetrahydro-5H-cyclohepta[b]pyridine $\quad 7,5 \quad 5,6,7,8,9,10$-hexahy dro-5H-2,3cycloocta[$[b]$ pyridine $\mathbf{8},{ }^{5}$ and 5,6,7,8,910,11,12,13,14-decahydro-2,3-cyclododeca $[b]$ pyridine 9, ${ }^{7}$ respectively (Scheme 3). 


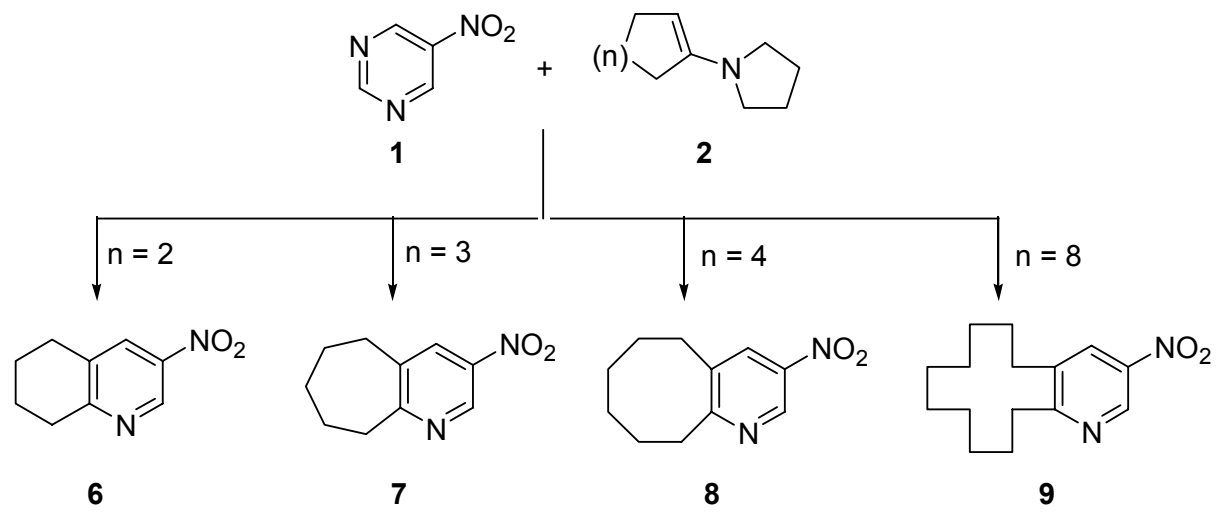

\section{Scheme 3}

A further application of this cycloaddition reaction provided the 3-nitro derivatives of 5,6,7,8-tetrahydro-8-methylquinoline 10, of 5,6,7,8-tetrahydro-5,8-methanoquinoline $\mathbf{1 1}$ and of 10,11-dihydro-5H-benzo [4,5]cyclohepta [1,2-b]pyridine $\mathbf{1 2}^{5}$ (Scheme 4).

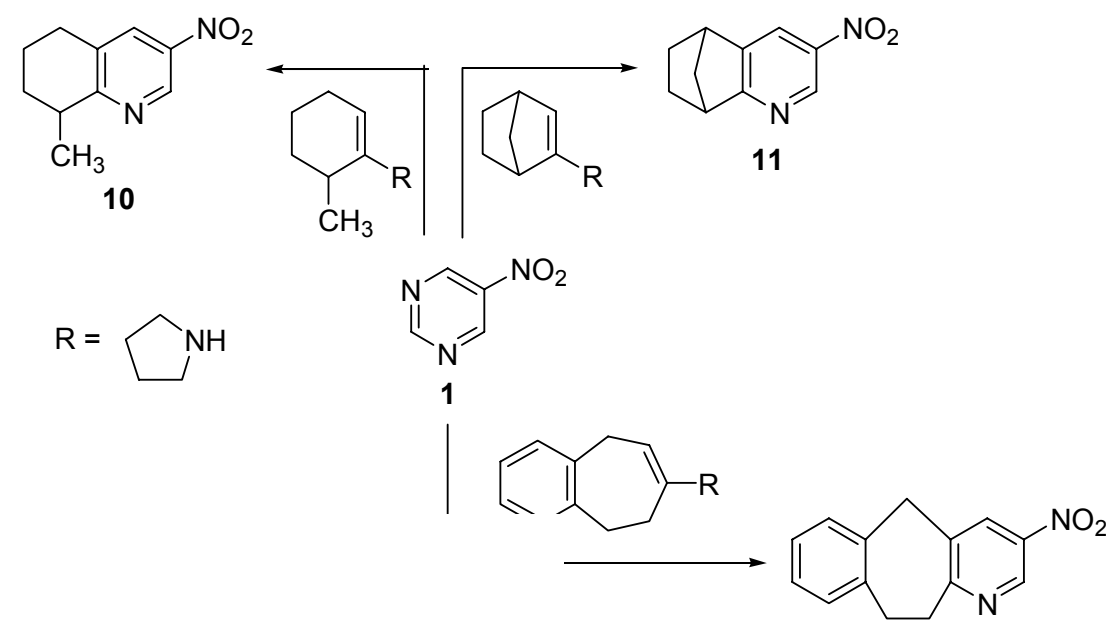

12

\section{Scheme 4}

A number of 2,3-cycloalkenopyridines has been reported to be formed by intramolecular cycloadditions reactions with inverse electron demand with pyrimidines and triazines containing a molecular chain of appropriate length between the heterocycle and the dienophile. Due to the entropic assistance of the molecular chain connecting the reactants the intramolecular cycloadditions are usually more reactive than the intermolecular cycloadditions. In general the effect of the tether on the reactivity of the Diels-Alder cycloadditions is the largest with a chain length of five or six atoms. The syntheses of 2,3-cycloalkenopyridines is most successful with pyrimidines and triazines substituted with an $\omega$-pentynyl or a $\omega$-hexynyl side chain. The electron 
rich acetylenic moiety present in the tether acts as the dienophile adding across the azadiene part of the heterocyclic ring. It creates a cycloadduct which after the retro Diels-Alder reaction yields the cycloalkenopyridine.

On heating of 5-R-2-(pent-4-yn-1-yl) pyrimidine $13 a-c$ at $210{ }^{\circ} \mathrm{C}$ in nitrobenzene under nitrogen in good yield the 5 -R-cyclopenta $[b]$ pyridine 15 a-c was obtained. ${ }^{8}$ The reaction probably occurs via the intermediacy of cycloadduct 14 which by expulsion of hydrogen cyanide yields the required product (Scheme 5). The rate of the reaction was dependent on the electronic character of substituent $\mathrm{R}(\mathrm{NO} 2>\mathrm{H}>\mathrm{Ph})$. The rate increase of the 5-nitro compound $\mathbf{1 3 b}$, compared to the unsubstituted one 13a is certainly due to the enhancement of the electron deficiency of the pyrimidine ring. The rate retarding effect of the 5-phenyl group in 13c may very probably be ascribed to its steric hindrance in the formation of the cycloadduct 14. Considerable rate enhancements are observed upon quaternization of the pyrimidine ring or on protonation, for example, when the reaction is carried out in trifluoroacetic acid. ${ }^{9}$

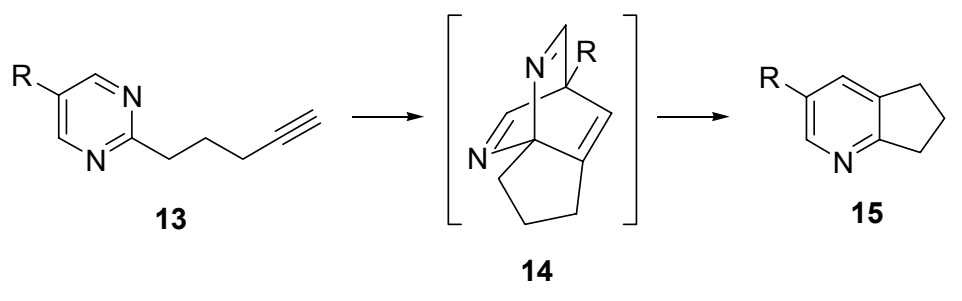

a) $\left.\mathrm{R}=\mathrm{H} ; \mathrm{b}) \mathrm{R}=\mathrm{NO}_{2} ; \mathrm{c}\right) \mathrm{R}=\mathrm{Ph}$

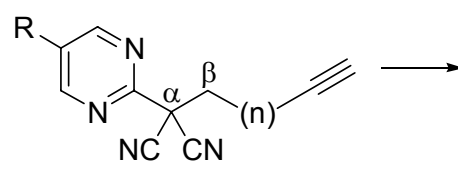

16

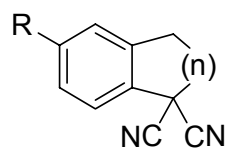

17

a) $\mathrm{R}=\mathrm{H} ; \mathrm{b}) \mathrm{R}=\mathrm{NO}_{2} ;$ c) $\mathrm{R}=\mathrm{Ph} \quad$ a) $\left.\mathrm{n}=1 ; \mathrm{b}\right) \mathrm{n}=2$

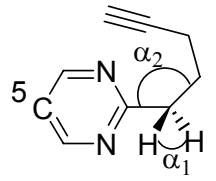

A $\quad \alpha_{1}(B)>\alpha_{1}(A)$ $\alpha_{2}(B)<\alpha_{2}(A)$

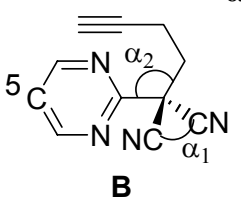

\section{Scheme 5}

A strong rate accelerating effect was observed when in the $\alpha$ position of the side chain dicyano groups are present. This rate effect was also observed in the chemistry of the 1,2,4triazines. ${ }^{3}$ Heating of 2-(1,1'-dicyanopent-4-yn-1-yl)pyrimidines $\mathbf{1 6}(\mathrm{n}=1)$ at $130^{\circ} \mathrm{C}$ provided in excellent yields the dicyanocylopenta $[b]$ pyridine, i.e $\mathbf{1 7}(\mathrm{n}=1)$. Similarly from the 2hexynylpyrimidine $\mathbf{1 6}(\mathrm{n}=2)$ the corresponding 8,8-dicyano-5,6,7,8-tetrahydroquinoline $\mathbf{1 7}(\mathrm{n}=2)$ was obtained $^{8}$ (Scheme 5). The much lower temperature observed for the conversion of 16 $(\mathrm{R}=\mathrm{H}, \mathrm{n}=1)$ into $\mathbf{1 7}(\mathrm{R}=\mathrm{H}, \mathrm{n}=1)\left(130^{\circ} \mathrm{C}\right)$ compared to the conversion of $\mathbf{1 3}(\mathrm{R}=\mathrm{H})$ into $\mathbf{1 5}(\mathrm{R}=\mathrm{H})$ at $210^{\circ} \mathrm{C}$ was explained by the so-called Thorpe-Ingold effect, ${ }^{10}$ which suggests that the 
repulsion effect of the two neighbouring cyano groups reduces the internal $\mathrm{C} 2-\mathrm{C} \alpha-\mathrm{C} \beta$ angle, leading to a closer proximity of the acetylenic reaction center to the $\mathrm{C} 2$ and $\mathrm{C} 5$ of the pyrimidine ring (compare structures $\mathrm{A}$ and $\mathrm{B}$ in Scheme 5). It results in added entropic assistence and consequently rate enhancement. An alternative explanation concerns the change of the conformational equilibria of the electron-rich side chain connected with the electron-poor pyrimidine. It has been suggested ${ }^{8}$ that the reactive syn rotamers are higher populated due to the presence of cyano substituents connecting the reaction centers. ${ }^{11,12}$

\section{From 1,2,3-triazines}

1,2,3-Triazine 18, when reacting with the pyrrolidinocycloalkenes $(\mathbf{2}, \mathrm{n}=1,2,4,6,8)$ in dry chloroform at $100-120^{\circ} \mathrm{C}$ gives, usually in moderate-to-poor yields, the corresponding 2,3cycloalkenopyridines 19. ${ }^{13,14}$ The reaction can be described to occur by cycloaddition across the N-3 and C-6 of the 1,2,3-triazine ring, whereby the nucleophilic carbon of the dienophile is attached to C-6 (Scheme 6). Loss of nitrogen and pyrrolidine gave the required product. Similar reactions were also reported with the 3-methyl-, 4-methyl- and 4,6-dimethyl-1,2,3-triazine, although the rate of the reaction is lower due to the electron donating influence of the methyl Group, requiring more energetic reaction conditions. Trimethyl-1,2,3-triazine is unreactive. It has been reported that under microwave irradiation a dramatic shortening of reaction time can be achieved. $^{15}$

The property of $\mathbf{1 8}$ to undergo inverse cycloadditions has been found a useful application in the synthesis of the quinoline derivative $\mathbf{2 1}$, the key intermediate in the synthesis of the alkaloids tortuosamine $22(\mathrm{R}=\mathrm{H}), \mathrm{N}$-formyltortuosamine $22(\mathrm{R}=\mathrm{CHO})$ and $\mathrm{N}$-acetyltortuosamine 22 $\left(\mathrm{R}=\mathrm{COCH}_{3}\right) \quad$ (Scheme 6). Heating 18 with the pyrrolidine eneamine of 1-(3',4'dimethoxyphenyl)-4-oxocyclohexane carbonitrile $\mathbf{2 0}$ at $100-110^{\circ} \mathrm{C}$ in a sealed tube gave the quinoline derivative $21 .^{13}$

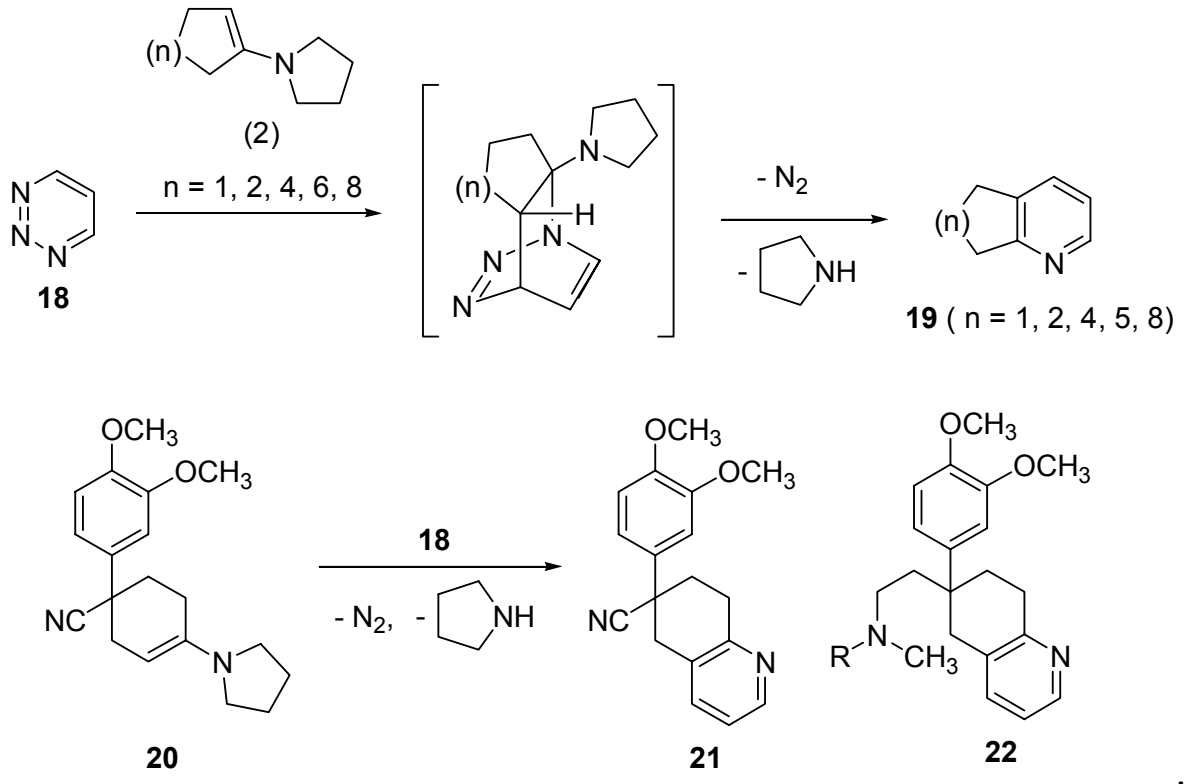

\section{Scheme 6}


Extension of this work showed that the mode of cycloaddition is temperature dependent. ${ }^{16}$ Whereas heating of 4-methyl-1,2,3-triazine 23 with 1-pyrrolidinocycloctene at $100^{\circ} \mathrm{C}$ in benzene for a few hours gave the 2-methylcycloocta[b]pyridine $\mathbf{2 4}$, heating in a high boiling solvent at $200^{\circ} \mathrm{C}$ gave a mixture of $\mathbf{2 4}$ and the isomeric 4-methylderivative $\mathbf{2 5}^{5 \mathrm{c}}$. This result shows that at elevated temperatures besides addition across the N-3/C-6 (intermediate A), leading to 24, addition also takes place across N-1/C-4 (intermediate B) (Scheme 7). This result was usefully applied to prove the structure of the alkaloids onychine $(\mathbf{2 8}, \mathrm{R}=\mathrm{H})$ and 6-methoxyonychine (28, $\left.\mathrm{R}=\mathrm{OCH}_{3}\right)($ Scheme 7$) .{ }^{16}$ Reaction of $\mathbf{2 3}$ with the pyrrolidine enamine of 1-indanone gave a mixture of 1-methyl-4-azafluorene 26 and 3-methyl-4-azafluorene 27. Oxidation of 26 with potassium permanganate gave the onychine alkaloid 28.

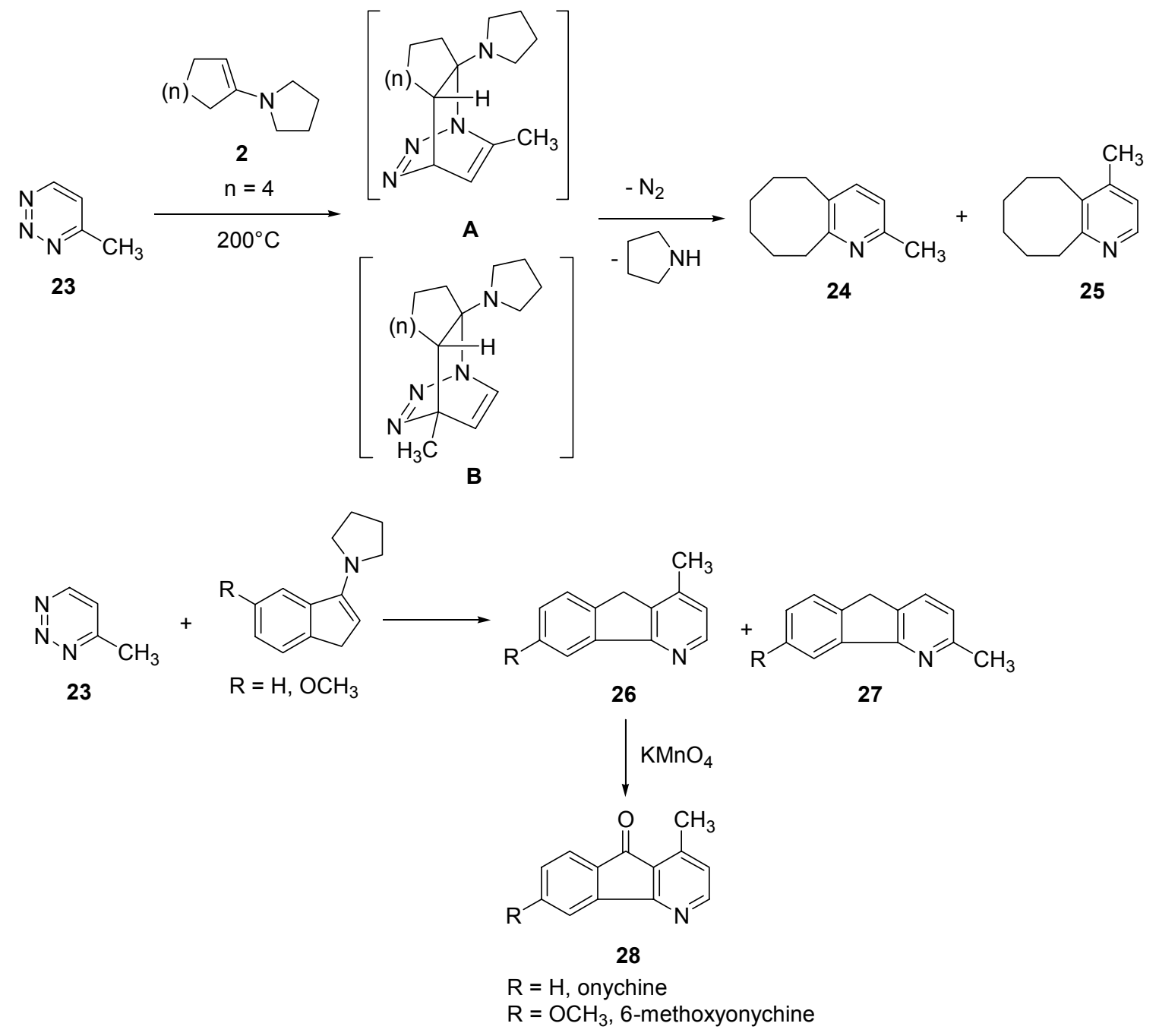

\section{Scheme 7}




\section{From 1,2,4-triazines}

Intramolecular cycloaddition reactions have been reported with 1,2,4-triazines having at position 3 an alkynyl side chain being unsubstituted or substituted in the $\alpha$ position of the side Chain. ${ }^{3}$ These compounds 30 were prepared by nucleophilic displacements of methyl sulphinate in 3methylsulphonyl-1,2,4-triazine 29 by a base induced reaction with an alkyne bearing two activating groups. Mild heating of compound $\mathbf{3 0}(\mathrm{n}=1)$ and $\mathbf{3 0}(\mathrm{n}=2)$ gave in reasonable yields the cylopenta[b]pyridines 31( $\mathrm{n}=1)$ and 5,6,7,8-tetrahydroquinolines 31( $\mathrm{n}=2)$ (Scheme 8). ${ }^{3}$

Another approach to construct a reactive side chain at position 3 of the triazine ring was the replacement of hydrogen at position 3 in $\mathbf{3 2}$ by the methylsulphonyl group using the vicarious $\mathrm{S}_{\mathrm{N}} \mathrm{H}$ substitution methodology with $\alpha$-chloromethyl phenyl sulphone. ${ }^{17,18}$ By a reaction of 33 with iodoalkyne the 3-( $\alpha$-sulphonylalkynyl)-1,2,4-triazine 34 was prepared (Scheme 8).

Heating of compound $\mathbf{3 4}(\mathrm{n}=1)$ in bromobenzene at reflux temperature gave the corresponding cyclopenta[b]pyridine $\mathbf{3 5}(\mathrm{n}=1)$ in reasonable yields. The reaction involves a cycloadduct which after expulsion of nitrogen gives the required product. Similarly from $\mathbf{3 4}(n=2)$ the 8-methylsulfonyl-5,6,7,8-tetrahydroquinolines $\mathbf{3 5}(n=2)$ are obtained. ${ }^{19}$ As expected the rate of formation of the tetrahydroquinolines was substantially lower than that of the cyclopenta $[b]$ pyridines due to the longer carbon chain linking the diene and the acetylenic Group, retarding the formation of the cycloadduct.
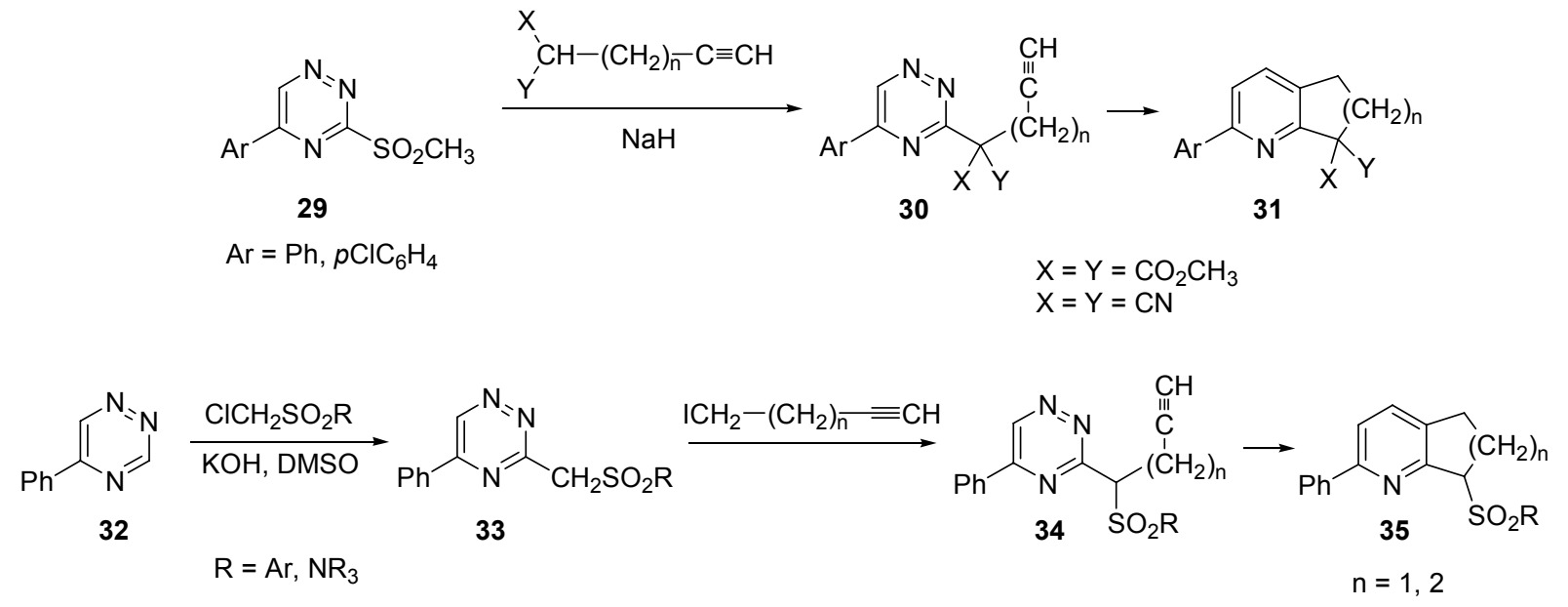

\section{Scheme 8}

\section{3,4-Cycloalkenopyridines}

\section{From 1,2,4-triazines}

Reaction of 5-acyl-1,2,4-triazines 36a-d with $\mathbf{2}(\mathrm{n}=1)$ in ethanol or in dry dioxane at room temperature affords 3-acyl-5,6-dihydro-7H-cyclopenta[c]pyridines 38a-d. These products result from a regiospecific addition of the double bond of the eneamine to C-3 and C- 6 of the triazine 
ring, yielding cycloadducts 37 , which by nitrogen expulsion and pyrrolidine elimination convert to the cyclopenta $[c]$ pyridine derivatives 38 (Scheme 9) ${ }^{20}$ Similarly, reaction of $\mathbf{3 6 a - c}$,e with 1pyrrolidinocyclohexene $\mathbf{2}(\mathrm{n}=2) \quad$ provides the corresponding 3-acyl-5,6,7,8tetrahydroisoquinolines $39 \mathrm{a}-\mathrm{c}, \mathrm{e}^{20}$ The rate of the transformation is lower than the reaction with 1-pyrroldinocyclopentene, probably due to steric hindrance in the formation of the cyclohexenoadduct. It is of interest to mention that 3-acetyl-1-methylthio-5,6,7,8tetrahydroisoquinoline 39e is a useful key intermediate in the Fisher preparation of $2(3-(5,6,7,8-$ tetrahydroisoquinolinyl))indole 40, the precursor in the synthesis of the zwitterionic indole alkaloid sempervirine 41 (Scheme 9). ${ }^{21}$ Using the same methodology also the seven- and eightmembered analogs of sempervirine, i.e. $\mathbf{4 2}$ and $\mathbf{4 3}$ are also prepared. ${ }^{22}$

It is of interest to mention that from the reaction mixture, obtained when reacting 5-cyano-3isopropylthio-1,2,4-triazine $\mathbf{4 4}$ with 1-pyrrolidinocyclohexene $\mathbf{2}(\mathrm{n}=2)$ not the expected 3-cyano1isopropylthioisoquinoline 47 was obtained, but an isomeric mixture of the addition products 3cyano-1-isopropylthio-4a,5,6,7,8,8a-hexahydro-8a-pyrrolidino- isoquinoline 46a and 46b. ${ }^{18}$ They are formed after nitrogen extrusion from the highly strained cycloadduct 45 (Scheme 10). The formation of $\mathbf{4 6}$ is one of the few examples of a reaction in which the precursor of the final product could be isolated. Treatment of $\mathbf{4 6}$ with acid gives $\mathbf{4 7}$.

An interesting application of this methodology concerns the preparation of the symmetrical and unsymmetrical, annelated 2,2'-bipyridines from 5,5'-bi-1,2,4-triazines. Heating 3,3'-(bis methylthio)-5,5'-bi-1,2,4-triazine 48 with the pyrrolidinocyclopentene $2(\mathrm{n}=1)$ at $130^{\circ} \mathrm{C}$ in the absence of a solvent the 1,1-bis(methylthio)-3,3'-bi(cyclopenta[c]pyridine $\mathbf{4 9}(\mathrm{n}=1)$ is obtained in good yield (Scheme 11) 23, 24, 25. Similarly, reaction of $\mathbf{4 8}$ with the six- and seven-membered enamines $2(\mathrm{n}=2)$ and $\mathbf{2}(\mathrm{n}=3)$ gives at somewhat higher temperatures the corresponding 3,3'bi(cyclohexa[c]- and cyclohepta[c]pyridines $49(\mathrm{n}=2)$ and $49(\mathrm{n}=3)$ respectively. The course of these cycloaddition reactions is found to be solvent dependent. 


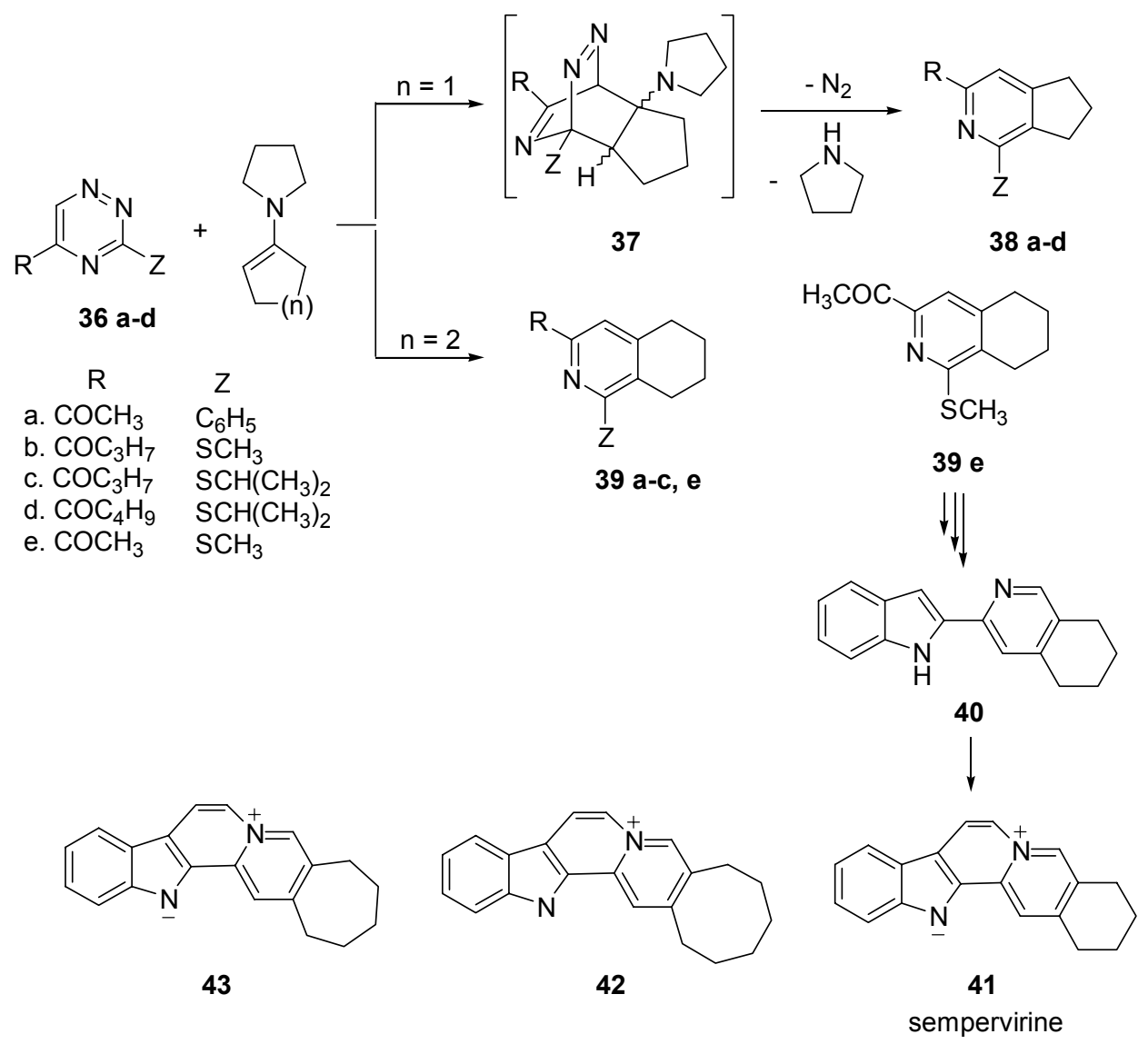

\section{Scheme 9}

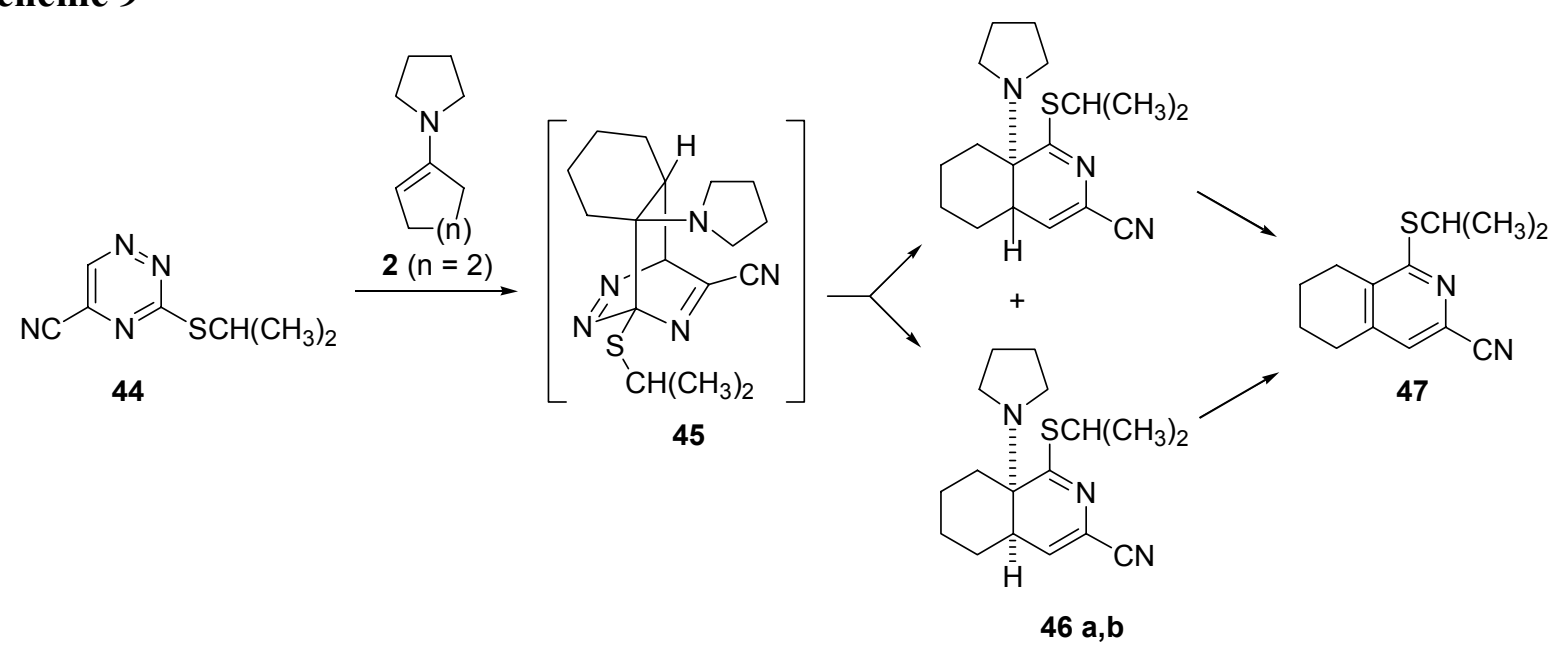

\section{Scheme 10}

Reaction of 48 with the eneamines $2(n=1,2,3)$, carried out in boiling dioxane, resulted in the conversion of only one triazine ring into the pyridine ring; 1,2,4-triazinylcycloalka[c]pyridines $\mathbf{5 0}(n=1,2,3)$ a bi(cyclohexa[c]- and cyclohepta[c]pyridines $49(n=2)$ and $49(n=3)$ respectively. 
The course of these cycloaddition reactions is found to be solvent dependent. Reaction of $\mathbf{4 8}$ with the eneamines $2(n=1,2,3)$, carried out in boiling dioxane, resulted in the conversion of only one triazine ring into the pyridine ring; 1,2,4-triazinylcycloalka[c]pyridines $\mathbf{5 0}(\mathrm{n}=1,2,3)$ are formed. Enhancing the electron-deficiency of the triazine ring by oxidation of the methylthio group into the methylsulfonyl substituent, $\mathbf{5 1}$ yields with the eneamine $\mathbf{2}(\mathrm{n}=1,2,3)$ the unsymmetrical annelated 2,2'-bipyridines 52. The compounds 52 with ring $A(n=1)$ and ring $B(n=2)$, with ring $A(n=1)$ and ring $B(n=3)$ and with ring $A(n=2$ and ring $B(n=3)$ have been synthesised (Scheme $11)$.
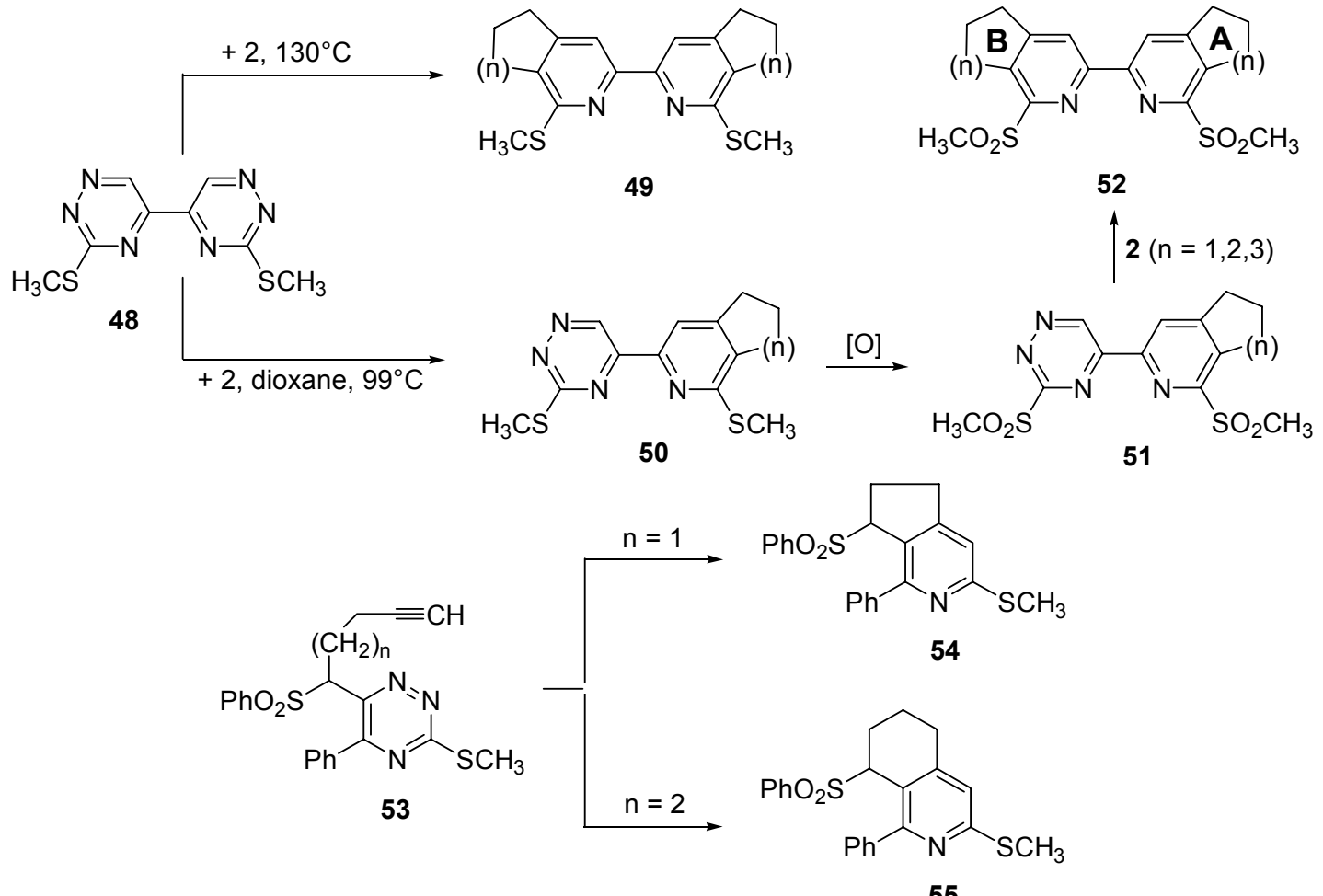

51

\section{Scheme 11}

A few 3,4-cycloalkenopyridines are formed from 1,2,4-triazines, containing at position 6 the $\alpha$-sulphonylalkynyl substituent. Compound $\mathbf{5 3}(\mathrm{n}=1,2)$, obtained by a vicarious $\mathrm{SnH}$ substitution of 3-methylthio-5-phenyl-1,2,4-triazine with a-chloromethyl phenyl sulphone and subsequent treatment with a iodoalkyne gave on heating the 3,4-cycloalkenopyridine $\mathbf{5 4}$ or the 5,6,7,8tetrahydroisoquinoline $\mathbf{5 5}$ respectively, in low yields (Scheme 11). ${ }^{19}$

Interestingly, it has been reported that the highly electron-deficient trichloro-1,2,4-triazine 56 is able to react with unactivated cyclic olefins such as cyclopentene, cycloheptene, cyclooctene and cyclododecene into 3,4-cycloalkeno-2,6-dichloropyridines $\mathbf{5 9}^{26,27}$. It is suggested that the initial addition takes place across $\mathrm{C}-3$ and $\mathrm{C}-6$, leading (after loss of nitrogen) to the 
dihydropyridine 57. Aromatisation into 59 occurs via a [1,5] sigmatropic hydrogen shift of 57 into 58 and subsequent loss of hydrogen chloride (Scheme 12). The azadiene structure in intermediate $\mathbf{5 7}$ can react further, when $\mathbf{5 6}$ reacts with cyclopenta-1,3-diene. The trichlorotriene 60 could be isolated.<smiles></smiles>

56<smiles>ClC1=C(Cl)[C@H]2C[Te]C[C@H]2C1</smiles>

57

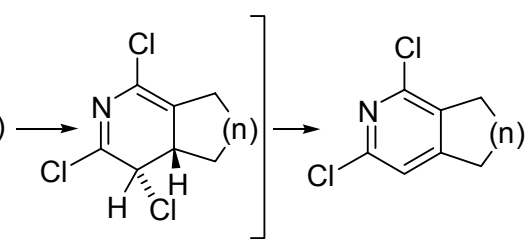

58

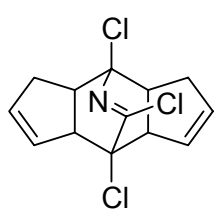

60

\section{Scheme 12}

\section{2,3- And 3,4-cycloalkenopyridines mixture}

There is one report in the literature in which in a cycloaddition reaction a mixture of 2,3- and 3,4cycloalkenopyridines is obtained. It concerns the reaction of the dicyanoalkynylpyrazine $\mathbf{6 1}$, which on heating gives a mixture of the 2,3- and 3,4-(1,1-dicyanocyclopenteno)pyridine 63 and 64 respectively. ${ }^{28}$ It is evident that both compounds originate from intermediate $\mathbf{6 2}$ by loss of hydrogen cyanide which can take place via bond breaking A or B. An interesting extension of the reaction is the behaviour of the 2,6-di(1,1-dicyanopentynyl) pyrazine $\mathbf{6 5}$, which at $130^{\circ} \mathrm{C}$ undergoes conversion into the mixture of 66 and 67 , but on heating at $210^{\circ} \mathrm{C}$ yields the tetracyanotetrahydro-s-indacene 68. The compounds 66 and 67 are intermediates in the formation of $\mathbf{6 8}$, since each of them on heating at $210^{\circ} \mathrm{C}$ gives $\mathbf{6 8}$ (Scheme 13). 

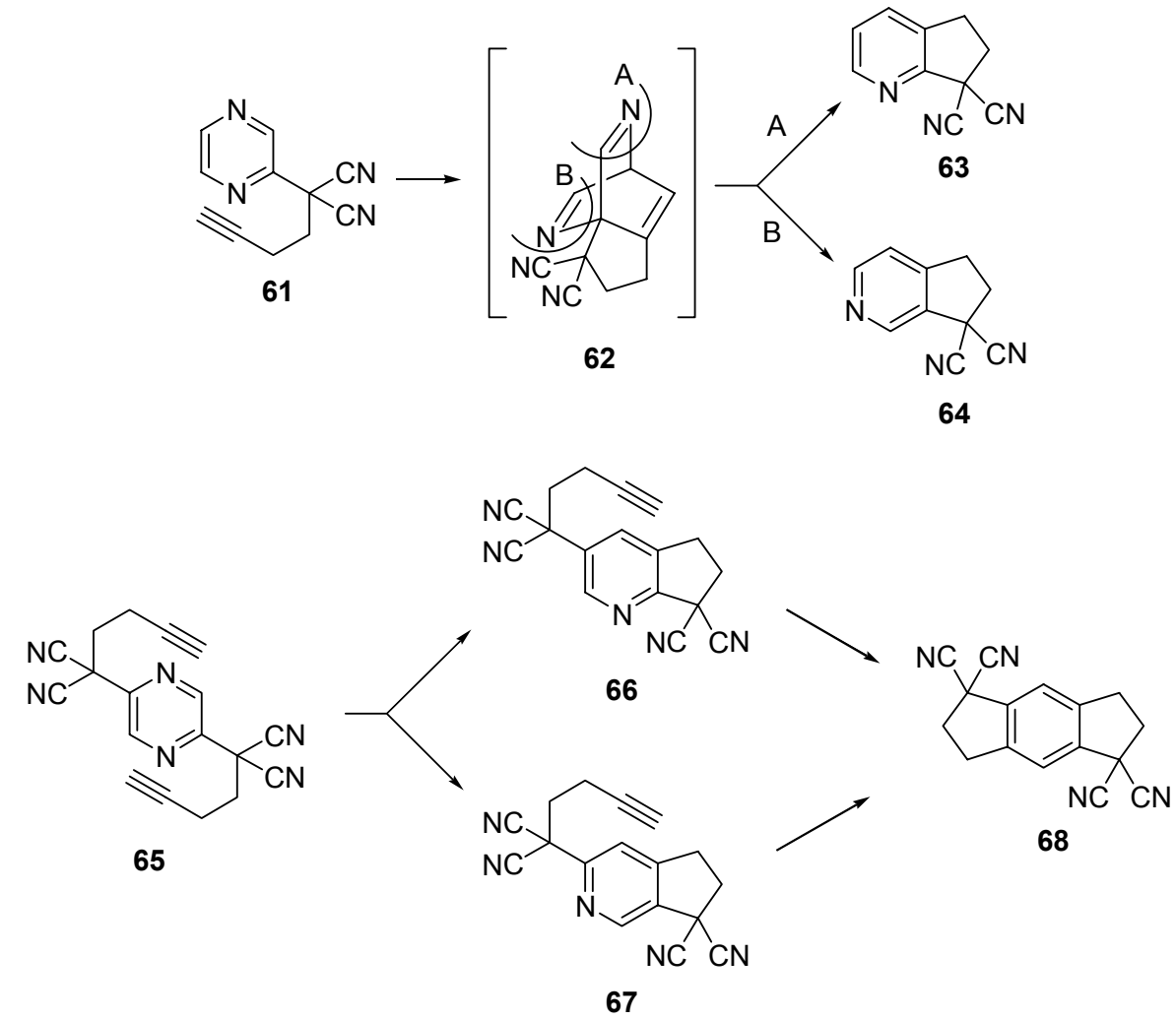

\section{Scheme 13}

\section{References}

1. Thummel, R. P. Carbocyclic Annelated Pyridines. In: Pyridine and its Derivatives, Part 5 Ed. Vol 14, in the series Newkome, G. R. The Chemistry of Heterocyclic Compounds.

2. (a) Boger, D. L. Chem. Rev. 1986, 86, 781. (b) Boger, D. L.; Weinreb, S. N. In: Hetero Diels-Alder Methodology in Organic Synthesis, Wasserman, H. H., Ed.,Academic: New York, 1987; p 323.

3. Taylor, E. C.; Macor, J. E.; French, L. J. Org. Chem. 1991, 56, 1807.

4. Marcelis, A. T. M.; van der Plas, H. C. Trends in Heterocyclic Chemistry 1991, 111.

5. Marcelis, A. T. M.; van der Plas. H. C. Tetrahedron 1989, 45, 2693.

6. van der Plas H. C.; Marcelis, A. T. M.; van den Ham, D. M. W.; Verhoeven, J. W. J. J. Org. Chem. 1986, 51, 4070.

7. Shkil, G.; Sagitullin, R. S. Tetrahedron Lett. 1994, 35, 2075.

8. Frissen, A. E.; Marcelis, A. T. M.; de Bie, D. A.; van der Plas, H. C. Tetrahedron 1989, 45, 5151.

9. Frissen, A. E.; Geurtsen, G.; Marcelis, A. T. M.; van der Plas, H. C. Tetrahedron 1990, 46, 595.

10. Beesley, R. M.; Ingold, C. K.; Thorpe, J. F. J. Chem. Soc. 1915, 107, 1080. 
11. Jung, M. E.; Gervay, J. Tetrahedron Lett. 1988, 2429.

12. Sternbach, D. D.; Rossana, D. M.; Onan, K. D. Tetrahedron Lett. 1985, 591.

13. Okatani, T.; Koyama, J.; Tagahara, K. Heterocycles 1989, 29,1809.

14. Sugita, T.; Koyama, J.; Tagahara, K.; Suzuta, Y. Heterocycles 1985, 23, 2789

15. Diaz-Ortiz, A.; de la Hoz, A.; Prieto, P.; Carillo, J. R.; Moreno, A.; Neunhoeffer, H. Synlett 2001, 236

16. Okatani, T.; Koyama, J.; Suzuta, Y.; Tagahara, K. Heterocycles 1988, 27, 2213.

17. Makosza, M.; Wojciechowski, M. Heterocycles 2001, 54, 445.

18. Rykowski, A.; Branowska, D.; Makosza, M.; van Ly, P. J. Heterocyclic Chem. 1996, 33, 1567.

19. Branowska, D.; Ostrowski, S.; Rykowski, A. Chem. Pharm. Bull. 2002, 50, 461.

20. Rykowski, A.; Lipinska, T. Polish J. Chem. 1997, 71, 83.

21. (a) Rykowski, A; Lipinska, T. Synthetic Comm. 1996, 26, 4409. (b) Rykowski, A.; Olender, E.; Branowska, D.; van der Plas, H. C. Oppi Briefs 2001, 33, 501.

22. (a) Lipinska, T. Tetrahedron Lett. 2002, 43, 9565. (b) Lipinska, T. Tetrahedron 2006, 62, 5736.

23. (a) Rykowski, A.; Branowska, D.; Kielak, J. Tetrahedron Lett. 2000, 41, 3657. (b) Branowska, A; Kielak, D. Polish J. Chem., 2000, 77, 1149. (c) Branowska, D.; Rykowski, A. Synlett 2002,1892.

24. Branowska, D. Synthesis 2003, 2096.

25. Branowska, D. Tetrahedron 2004, 60, 6021

26. Barlow, M. G.; Haszeldine, R. N.; Simpkin, D. J. J. Chem. Soc., Perkin Trans. 1982, 1245.

27. Barlow, M. G.; Sibous, L.; Suliman, N. N. E.; Tipping, A. E. J. Chem. Soc., Perkin Trans. 1996, 519.

28. de Bie, D. A.; Ostrowicz, A.; Geurtsen, G.; van der Plas, H. C. Tetrahedron 1988, 44, 2977. 